\title{
Desenvolvimento de PVC Reforçado com Fibras de Vidro Longas para Fabricação de Produtos Moldados
}

\author{
Leandro H. Grizzo, Elias Hage Junior \\ Programa de Pós-Graduação em Ciência e Engenharia de Materiais, UFSCar \\ Rafael V. Laurini \\ Braskem S.A.
}

\begin{abstract}
Resumo: Neste trabalho foi desenvolvido um método para reforçar PVC rígido com fibras de vidro longas através da incorporação pelo processo de recobrimento da fibra contínua com um composto de PVC plastificado. Posteriormente o filamento foi picotado para a formação de grânulos, com fibras de vidro já incorporadas, que foram misturados mecanicamente ao PVC rígido granulado para alimentação direta por moldagem. A moldagem por injeção direta foi realizada com sucesso não sendo necessário a compostagem prévia, o que foi considerado conveniente, pois reduziu as etapas de processamento da resina de PVC e que proporcionou, possivelmente, redução de custos, redução da degradação do comprimento médio das fibras de vidro e diminuição da possibilidade de degradação da resina de PVC. O reforçamento do PVC rígido com $20 \%$ em massa de fibras de vidro longas de comprimento inicial entre 13 e $14 \mathrm{~mm}$ resultou em adequadas propriedades mecânicas, bem superiores ao PVC rígido não reforçado. Os módulos (tração e flexão) e a resistência ao impacto Charpy praticamente dobraram, mesmo com os compósitos apresentando grande quantidade de plastificante em sua formulação, que possibilita ao PVC ser utilizado em outras aplicações não antes possíveis como em peças técnicas de engenharia.
\end{abstract}

Palavras-chave: Poli (cloreto de vinila), PVC reforçado, fibra de vidro longa, propriedades mecânicas, compósitos.

\section{Long Glass Fiber Reinforcement of PVC Molding Compounds}

\begin{abstract}
In this paper, a method to reinforce rigid PVC with long glass fibers (LGF) was developed through the incorporation of continuous glass fibers, as rovings, with plasticized vinyl matrix prepared by the wire coating technique. The plasticized vinyl rovings were pelletized. The pellets $(13-14 \mathrm{~mm})$ were then blended to a granulated rigid PVC formulation and directly injection molded as testing specimens. The direct injection molding, eliminating the preliminary melt-compounding process, was achieved successfully, which was considered convenient because it reduced the number of processing steps, which allowed cutting expenses, reduced the deterioration of the glass fibers' length and reduced the possibility of PVC resins' degradation. $20 \mathrm{w} / \mathrm{w}$ (\%) long glass fiber reinforced rigid PVC (LGF/PVC) composites were then obtained with twice as high modulus and Charpy's impact strength compared to the unreinforced rigid PVC even with the composites were formulated with a high quantity of plasticizer. As a result, PVC can be used in unrecognized high-performance applications that were not possible before.
\end{abstract}

Keywords: Poly(vinyl chloride), reinforced rigid PVC, long glass fiber (LGF), mechanical properties, composites.

\section{Introdução}

Nos últimos anos tem ocorrido um rápido crescimento no desenvolvimento e aplicação de compósitos poliméricos com matrizes termoplásticas para uso em engenharia, devido a sua facilidade de conformação e fabricação/processabilidade, da obtenção de produtos leves em relação aos materiais tradicionais e da boa relação custo/desempenho mecânico.

O poli(cloreto de vinila), ou popularmente PVC ou vinil, é atualmente o segundo termoplástico mais consumido mundialmente, apresentando grande importância, principalmente nas áreas ligadas à construção civil, ao mercado calçadista, de laminados técnicos, etc. O PVC apresenta como principais características: versatilidade; isolamentos térmico, elétrico e acústico; resistência à propagação de chama; resistência química, às intempéries e à fluência; reciclabilidade, boa processabilidade, boa relação custo/benefício, entre outras ${ }^{[1]}$. Porém, seu baixo desempenho termo-mecânico e sua baixa rigidez em relação aos materiais tradicionais, torna-o inadequado para o uso em peças técnicas para aplicações de engenharia quando utilizado isoladamente.

Uma possível solução para a utilização de PVC em peças técnicas de engenharia é a incorporação de fibras de vidro ao composto rígido de PVC, que pode possibilitar alguns benefícios tais como: aumento na resistência mecânica, no módulo de elasticidade e/ou rigidez, na temperatura de termo-distorção (HDT), na estabilidade dimensional, na resistência à fluência e à fadiga, redução dos efeitos sob elevadas temperaturas e por tempos prolongados de carregamento, além da boa relação custo/ desempenho mecânico, que proporciona um maior valor agregado ao $\mathrm{PVC}^{[1-4]}$

Termoplásticos, como o PVC, são normalmente reforçados com fibras de vidro curtas ou mais recentemente, também reforçados com fibras de vidro longas, a fim de serem moldados. Fibras curtas (picadas, moídas ou em flocos) são geralmente compostadas com auxílio de extrusoras dupla rosca, formando grânulos cilíndricos de 3-5 mm de comprimento que apresentam fibras uniformemente distribuídas pelo seu volume. Reforçamento com fibras longas é usualmente denominado o processo em que fibras de vidro contínuas, como rovings, são incorporadas a matriz polimérica principalmente pelos métodos de pultrusão e wire coating technique (recobrimento fios e cabos), com subseqüente granulação para a formação de grânulos que apresentam as fibras orientadas paralelamente (continuamente) na direção longitudinal do pellet, de comprimento para moldagem por injeção, geralmente entre 10 e $12,5 \mathrm{~mm}^{[5-8]}$. 
Segundo Thomason ${ }^{[9-12]}$, os métodos que utilizam fibras longas produzem resultados de propriedades superiores aos compósitos termoplásticos que incorporam fibras curtas, pois existe a possibilidade de incorporação com uma concentração maior utilizando fibras de vidro longas (0-70\% em massa) em relação às fibras curtas (0-40\% em massa). Também a incorporação com fibras longas reduz a degradação do comprimento médio final das fibras possivelmente em virtude do recobrimento prévio com a matriz antes do processamento possibilitar uma maior proteção às fibras.

As principais dificuldades encontradas para o reforçamento do PVC com fibras de vidro foram: a elevada viscosidade do PVC fundido; a estreita janela de processabilidade do PVC rígido - elevada sensibilidade à degradação termo-mecânica, que será ainda mais restrita com a presença da fibra de vidro-; e a não disponibilidade de fibras de vidro adequadas para PVC no mercado brasileiro ${ }^{[13]}$. Essas dificuldades são refletidas na carência de artigos científicos sobre compósitos de PVC reforçados com fibra de vidro ${ }^{[14-17]}$.

O desafio principal deste trabalho foi incorporar a fibra de vidro ao PVC fundido, que possui alta viscosidade, sem promover a quebra acentuada da fibra que reduz o seu desempenho mecânico. Para isto, foi proposto revestir a fibra de vidro contínua com um composto de PVC com formulação adequada, utilizando o método de recobrimento de fios (wire coating), seguido de picotamento para a formação de grânulos com fibras de vidro já incorporadas, que puderam ser alimentados diretamente nos equipamentos de transformação. Inicialmente foi testada a injeção direta em virtude de serem reduzidas as etapas de processamento, o que diminui a possibilidade de degradação do composto e do comprimento final da fibra, aliado a redução dos custos de produção ${ }^{[18]}$.

O principal objetivo do trabalho foi promover o reforçamento do composto de PVC rígido através da introdução de fibras de vidro longas, de modo a produzir o melhor balanço de propriedades para aplicações estruturais em peças técnicas moldadas.

Tabela 1. Características da fibra de vidro (rovings).

\begin{tabular}{cc} 
Diâmetro do filamento $(\mu \mathrm{m})$ & 13 \\
Tex $\left(\mathrm{g} \cdot \mathrm{km}^{-1}\right)$ & 98 \\
Teor de umidade $(\%)$ & 0,004 \\
Teor de sólidos $(\%)$ & 0,08 \\
Mecha (filamentos por bundle) & 300 \\
Peso da bobina $(\mathrm{kg})$ & 5 \\
Altura $(\mathrm{mm})$ & 105 \\
Diâmetro externo $(\mathrm{mm})$ & 255 \\
Diâmetro interno $(\mathrm{mm})$ & 162 \\
\hline
\end{tabular}

\section{Materiais e Metodologia Experimental}

\section{Etapa 1: incorporação da fibra de vidro ao PVC através do processo wire coating e formação dos grânulos de fibra de vidro}

Primeiramente foram necessários os desenvolvimentos da fibra de vidro (FV) e da formulação do composto de PVC que pudesse vir a recobrir a fibra pelo processo wire coating.

A fibra de vidro utilizada foi desenvolvida pela Owens Corning, visto a não existência de fibras de vidro apropriadas para os compostos de PVC termoplásticos disponíveis no mercado brasileiro $^{[13]}$. As fibras de vidro para termoplásticos são fornecidas normalmente picadas, porém para o processo wire coating teria que ser disponibilizada e desenvolvida no formato de rovings para facilitar seu revestimento. Segundo a Owens Corning, as fibras de vidro Advantex ${ }^{\circledR}$ combinam as excelentes propriedades mecânicas e elétricas do tradicional vidro 'E' com a resistência à corrosão ácida do vidro 'E-CR', atendendo aos requerimentos ditados para ambos os vidros, tipo 'E' e 'E-CR', tanto na norma ISO 2078, como na ASTM D578-98. A Tabela 1 apresenta as principais características da fibra de vidro desenvolvida pela Owens Corning.

O desenvolvimento do composto foi realizado com a colaboração da empresa Karina Indústria e Comércio de Plásticos Ltda. Através de testes preliminares, os compostos de PVC com dureza 75 Shore A apresentaram melhores desempenhos em relação à processabilidade e à incorporação/molhabilidade da fibra de vidro. A partir dessa dureza, foram desenvolvidas três formulações, das quais uma era uma amostra padrão de PVC plastificado e nas outras duas foram adicionados duas diferentes resinas terpolímeros Vinisol $\mathrm{OH}$ (cloreto de vinila; acetato de vinila e hidroxi propil acrilato) e Vinisol $\mathrm{COOH}$ (cloreto de vinila; acetato de vinila e mono butil maleato), produzidas pela empresa Braskem, que tinham como objetivo atuar como compatibilizantes interfaciais. A idéia central do uso dos compatibilizantes era que os meros hidroxi propil acrilato e o mono butil maleato pudessem interagir com a base aminosilano presente na fibra de vidro enquanto que o mero cloreto de vinila do Vinisol interagisse com o cloreto de vinila do composto rígido de PVC (produzido na etapa 2), de modo a possibilitar uma compatibilização entre FV e matriz. As três diferentes formulações desenvolvidas são apresentadas na Tabela 2.

Após a produção dos compostos granulados de PVC plastificados, o próximo passo foi à incorporação da fibra de vidro realizada com a colaboração da empresa Lamine Tecnologia em Laminados Ltda. Os compostos granulados foram alimentados numa extrusora monorosca num processo semelhante ao de revestimentos de fios e cabos (wire coating), onde o composto flexível de PVC saía fundido (extrudado) pela matriz recobrindo a fibra, de modo a formar um fio contínuo de fibra de vidro revestida com PVC plastificado. A idéia central era que o composto de PVC, não só revestisse o roving

Tabela 2. Três formulações diferentes de compostos de PVC plastificados (Dureza Shore A 75) utilizadas para o recobrimento da fibra de vidro.

\begin{tabular}{|c|c|c|c|c|c|}
\hline \multicolumn{2}{|c|}{ Composto sem compatibilizante } & \multicolumn{2}{|c|}{ Composto com compatibilizante Vinisol $\mathrm{OH}$} & \multicolumn{2}{|c|}{ Composto com compatibilizante Vinisol $\mathrm{COOH}$} \\
\hline Formulação & pcr* & Formulação & per* & Formulação & per* \\
\hline Resina PVC (K 65) & 100 & Resina PVC (K 65) & 100 & Resina PVC (K 65) & 100 \\
\hline- & & Resina Vinisol OH & 10 & Resina Vinisol COOH & 10 \\
\hline Dioctil ftalato (DOP) & 50 & DOP & 50 & & 50 \\
\hline Óleo de soja epoxidado & 6 & Óleo de soja epoxidado & 6 & Óleo de soja epoxidado & 6 \\
\hline Sulfato tribásico de chumbo & 3 & Sulfato tribásico de chumbo & 3 & Sulfato tribásico de chumbo & 3 \\
\hline Estearina tripla pressão & 0,05 & Estearina tripla pressão & 0,05 & Estearina tripla pressão & 0,05 \\
\hline Master 06/965-PO & 0,028 & Master 06/965-PO & 0,028 & Master 06/965-PO & 0,028 \\
\hline
\end{tabular}

*pcr - partes por cem partes de resina, que representa a quantidade em massa do aditivo em relação a 100 unidades de massa da resina (PVC) ${ }^{[1]}$. 
semelhante a um fio, mas que pudesse penetrar entre as mechas de fibra de vidro, de modo a molhar a maior quantidade de fibras possíveis já as incorporando ao PVC. Esse fio contínuo foi picotado de modo a produzir três diferentes grânulos de FV (com fibras já incorporadas ao PVC), com comprimento na ordem de $13 \pm 1(\mathrm{~mm})$ :

- Grânulo de FV sem compatibilizante;

- Grânulo de FV com compatibilizante Vinisol OH;

- Grânulo de FV com compatibilizante Vinisol COOH.

\section{Etapa 2: preparação dos compostos rígidos de PVC}

Para a produção dos compostos rígidos de PVC, foram preparadas duas formulações diferentes de PVC, uma utilizada para compostos rígidos injetados e a outra sendo adicionado plastificante de modo que o composto final tivesse $11 \%$ em massa de DOP (dioctil ftalato) para servir como referência para os compostos com fibras de vidro (compósitos). As formulações são apresentadas na Tabela 3.

Os componentes da formulação foram adicionados na câmara cilíndrica de um misturador intensivo Mecanoplast ML-9 com resfriador vertical RH-20. Após mistura e resfriamento, os compostos dry-blend foram granulados em uma extrusora monorosca Miotto linha de granulação Grom 25 (L/D 25).

\section{Etapa 3: preparação das composições (compósitos)}

Para a preparação das composições foi utilizado o resfriador $\mathrm{RH}$ - 20 onde foram misturados mecanicamente por 20 segundos em baixa rotação o grânulo de fibra de vidro (etapa 1) com o composto granulado de PVC rígido (etapa 2) nas devidas proporções, de modo a fixar uma fração mássica de FV na composição. Para se fixar a fração de fibra foi considerado que o grânulo de FV era composto por $35 \%$ em massa de fibra e outros $65 \%$ de composto semi-flexível (30\% em massa de DOP), que corresponde a 19,5\% em massa de DOP no grânulo, assim quando se aumentava a fração de FV estava se aumentando a fração de plastificante no composto final. Portanto era importante existir um balanço entre o benefício proveniente da FV e o prejuízo causado pelo plastificante nas propriedades mecânicas. A fração escolhida foi de $20 \%$ em massa de FV de modo que o composto final apresentasse $11 \%$ em massa de DOP. Desse modo a fração de composto rígido foi de $43 \%$ em massa e de grânulo de FV de $57 \%$ em massa na composição final a ser injetada para a confecção dos corpos de prova para ensaios mecânicos e para temperatura de termo-distorção (HDT). Assim, ao final das três primeiras etapas foram produzidas cinco composições diferentes conforme o Quadro 1.

\section{Etapa 4: preparação dos corpos de prova para os ensaios mecânicos e HDT}

A injeção dos corpos de prova para os ensaios de tração, de flexão, de impacto e HDT foram realizados com sucesso numa injetora Sandretto Logica 770/170 operando no modo semi-automático utilizando condições empregadas industrialmente. Os parâmetros utilizados para os corpos de prova de tração tipo 1 foram os mesmos para os corpos de prova tipo barra (flexão, impacto e HDT).

\section{Resultados e Discussões}

\section{Propriedades mecânicas sob tração (ASTM D638)}

As Figuras 1-4 mostram o comportamento sob tração das diversas amostras. Pode-se notar que as amostras A, B e C apresentaram comportamento frágil, ou seja, logo que foi iniciado o escoamento, ocorreu ruptura do corpo de prova sem uma deformação considerável. Porém apresentaram elevado módulo e elevada resistência à tração. Já as amostras DOP e PVC Rígido apresentaram comportamento dúctil, sofrendo deformação significativa antes da ruptura, mas
Tabela 3. Formulação de um composto rígido de PVC e de um composto rígido de PVC com $11 \%$ em massa de DOP.

\begin{tabular}{|c|c|c|c|}
\hline \multirow[t]{2}{*}{ Componente } & \multicolumn{2}{|c|}{ Quantidade (pcr) } & \multirow[t]{2}{*}{ Função } \\
\hline & $\begin{array}{l}\text { Composto } \\
\text { rígido }\end{array}$ & $\begin{array}{c}\text { Composto } \\
\text { rígido com } \\
11 \% \mathrm{em} \\
\text { massa de } \\
\text { DOP }\end{array}$ & \\
\hline SP 700HF & 80 & 80 & $\begin{array}{c}\text { Resina de PVC K57 } \\
\text { (grade comum em injeção) }\end{array}$ \\
\hline S50SA & 20 & 20 & $\begin{array}{c}\text { Resina de PVC baixo } \\
\text { peso molecular } \\
\text { (K50, auxiliar de injeção) }\end{array}$ \\
\hline $\begin{array}{l}\text { Naftomix } \\
\text { PB2022 }\end{array}$ & 5 & 5 & $\begin{array}{l}\text { Estabilizante } \\
\text { térmico base } \mathrm{Pb}\end{array}$ \\
\hline $\begin{array}{c}\text { Ácido } \\
\text { esteárico }\end{array}$ & 0,3 & 0,3 & $\begin{array}{l}\text { Lubrificante } \\
\text { externo }\end{array}$ \\
\hline $\begin{array}{l}\text { Paraloid } \\
\text { K120 }\end{array}$ & 1 & 1 & $\begin{array}{c}\text { Auxiliar de } \\
\text { processamento }\end{array}$ \\
\hline DOP & - & 13,2 & Plastificante \\
\hline
\end{tabular}

Quadro 1. Composição das amostras moldadas.

\begin{tabular}{cc}
\hline Amostras & Composição \\
\hline DOP & PVC rígido com DOP (11\% em massa) \\
PVC rígido & PVC rígido \\
A & PVC rígido + Grânulo de FV sem \\
& compatibilizante* \\
B & PVC rígido + Grânulo de FV com \\
& compatibilizante Vinisol OH* \\
C & PVC rígido + Grânulo de FV com \\
& compatibilizante Vinisol COOH*
\end{tabular}

* Cada composição apresenta $20 \%$ em massa de fibra de vidro e $11 \%$ em massa de DOP.

apresentando módulo e resistência à tração bem inferior as amostras com fibra de vidro (A, B e C).

Os compósitos (A, B e C) apresentaram módulo $123 \%$ maior e resistência sob tração $30 \%$ maior que ambas as amostras sem fibras (PVC Rígido e DOP). A resistência sob tração para os compósitos foi a tensão na qual os compósitos sofreram fratura, enquanto que para as amostras PVC Rígido e DOP o limite de resistência a tração correspondeu à tensão onde se iniciou o escoamento (ponto de escoamento), ponto crítico de engenharia. O compósito $\mathrm{C}$ apresentou módulo e resistência sob tração superior a dos compósitos A e B, possivelmente devido à melhor adesão fibra-matriz. Os compósitos devidos suas maiores rigidez apresentaram deformações no limite de resistência a tração (fratura) bem inferiores as deformações (escoamento) das amostras dúcteis, DOP e PVC Rígido, 50 e 150\% respectivamente.

\section{Propriedades mecânicas sob flexão (ASTM D790)}

Nenhuma das amostras sob flexão sofreu ruptura, visto que o ensaio foi finalizado a 5\% de deformação. Sob flexão as amostras apresentaram comportamento dúctil como pode ser observado na Figura 5. Os módulos sob flexão dos compósitos $\mathrm{B}$ e $\mathrm{C}$ foram iguais e superiores as amostras DOP, PVC Rígido e A em aproximadamente 107, 91 e 25\%, respectivamente. A resistência sob flexão (ponto de escoamento) para o PVC Rígido não pode ser determinada. Os compósitos B e C praticamente apresentaram o mesmo desempenho, sendo superiores as amostras DOP e A em aproximadamente 10 e $23 \%$ respectivamente. A deformação da amostra DOP foi superior aos compósitos em aproximadamente $60 \%$. O módulo, a resistência sob flexão e a deformação no ponto de escoamento são mostrados nas Figuras 6-8, respectivamente. 


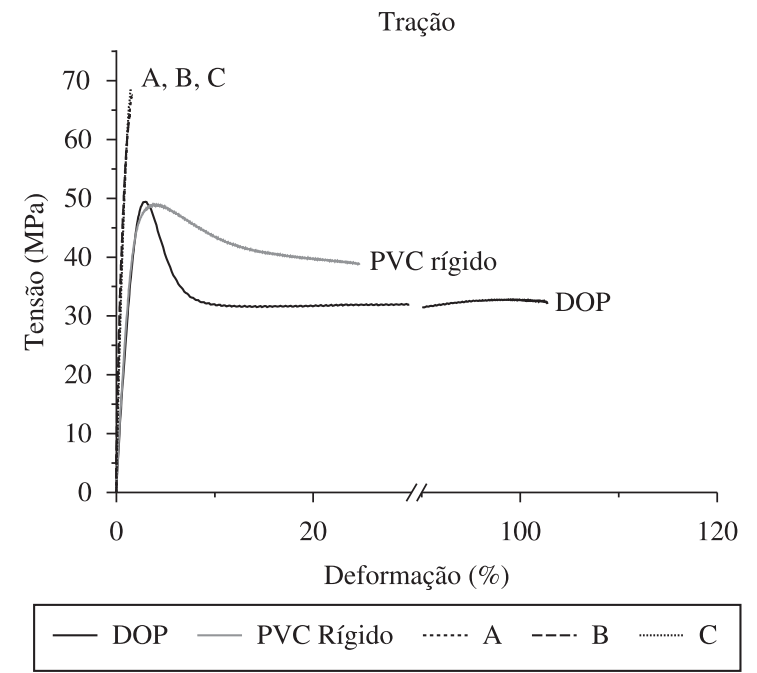

Figura 1. Curvas tensão em função da deformação sob tração para as diversas amostras: DOP; PVC Rígido; A; B e C.

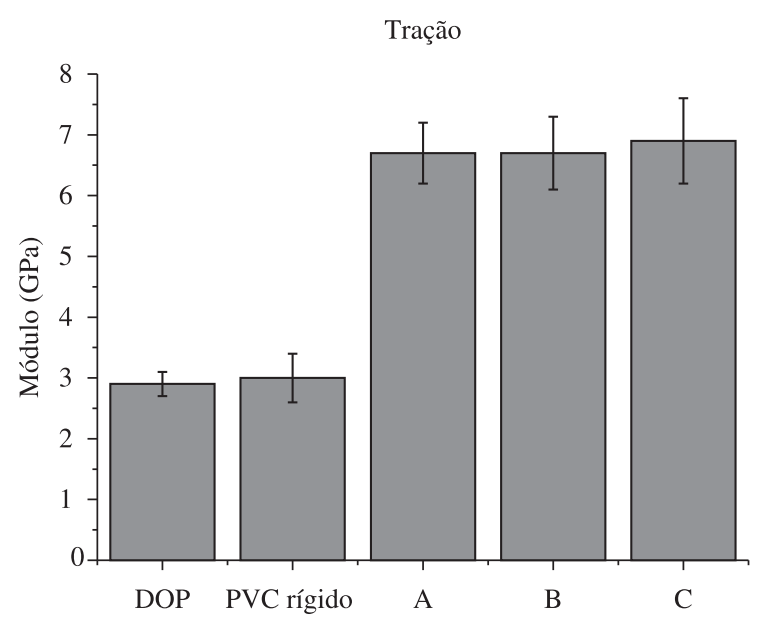

Figura 2. Módulo sob tração para as diversas amostras: DOP; PVC Rígido; A; B e C.

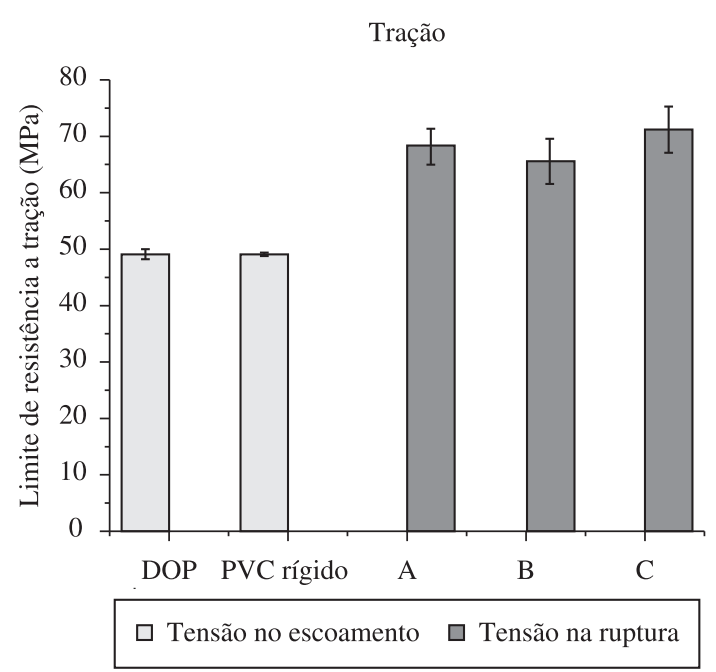

Figura 3. Limite de resistência a tração para as diversas amostras: DOP; PVC Rígido; A; B e C.

\section{Propriedades mecânicas sob impacto (ASTM D6110)}

Os compósitos apresentaram os melhores resultados entre as amostras sendo que a resistência ao impacto Charpy do compósito A foi superior as amostras $\mathrm{B} \mathrm{e} \mathrm{C}$, como pode ser visualizado na Figura 9. A amostra $\mathrm{C}$ apresentou desempenho inferior entre os compósitos possivelmente em virtude de apresentar um compatibilizante que aparentemente produziu uma melhor adesão fibra-matriz, e que causou uma diminuição do descolamento (debonding) e do arrancamento das fibras (pull out), reduzindo a resistência ao impacto. A amostra A apresentou resistência ao impacto Charpy superior aos compósitos B e C em aproximadamente 9 e $50 \%$, e em relação às amostras DOP e PVC Rígido em aproximadamente $280 \mathrm{e}$ $119 \%$ respectivamente.

\section{Temperatura de termo-distorção (HDT) (ASTM D648)}

A análise das temperaturas de termo-distorção permitiu definir que todas as amostras que apresentavam plastificantes (DOP, A, B, C) também apresentaram resultados de HDT inferiores ao do PVC Rígido (sem plastificante) 34, 42, 41 e 37\%, respectivamente.

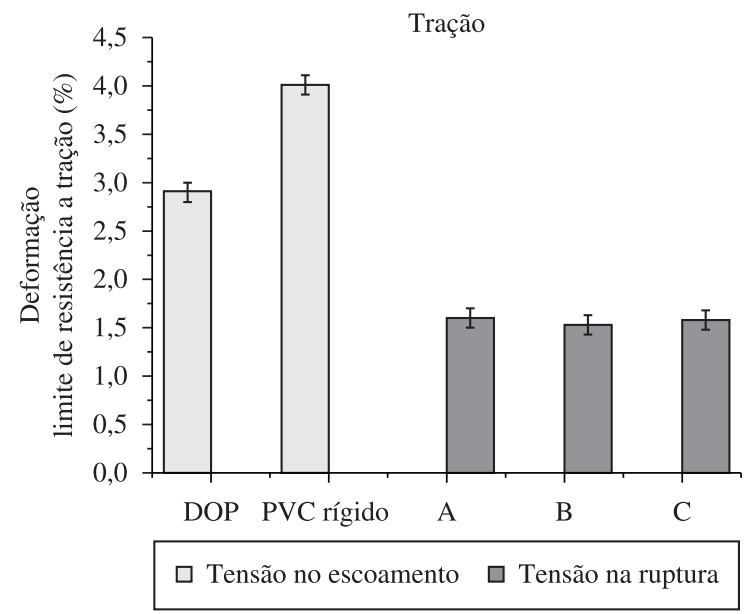

Figura 4. Deformação no limite de resistência a tração para as diversas amostras: DOP; PVC Rígido; A; B e C.

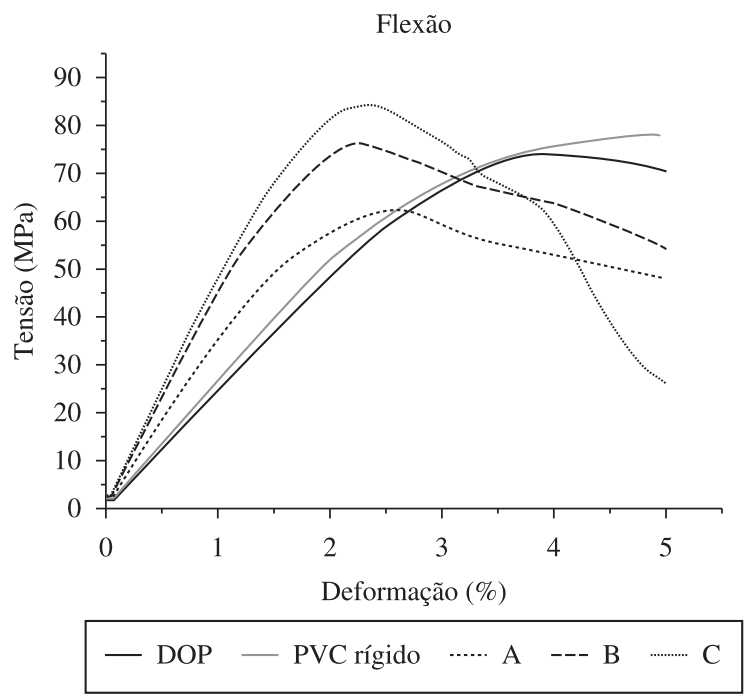

Figura 5. Curvas tensão em função da deformação sob flexão para as diversas amostras: DOP; PVC Rígido; A; B e C. 


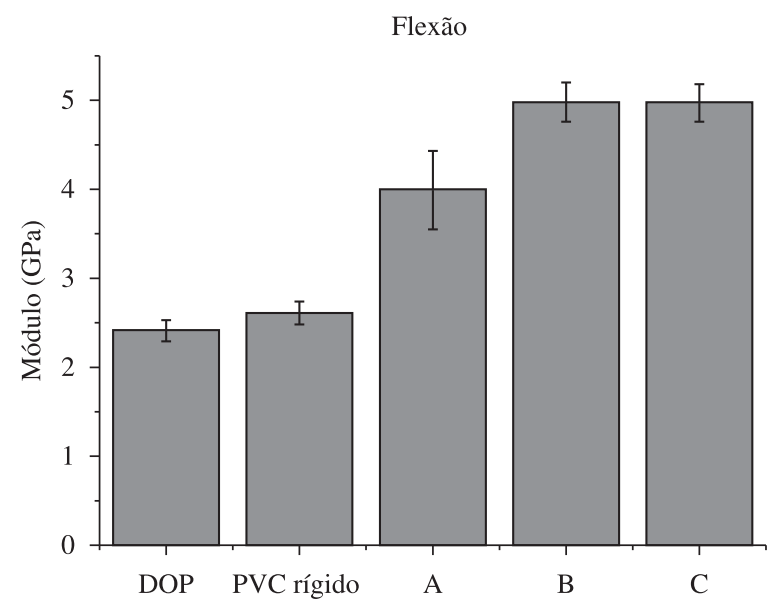

Figura 6. Módulo sob flexão para as diversas amostras: DOP; PVC Rígido; A; B e C.

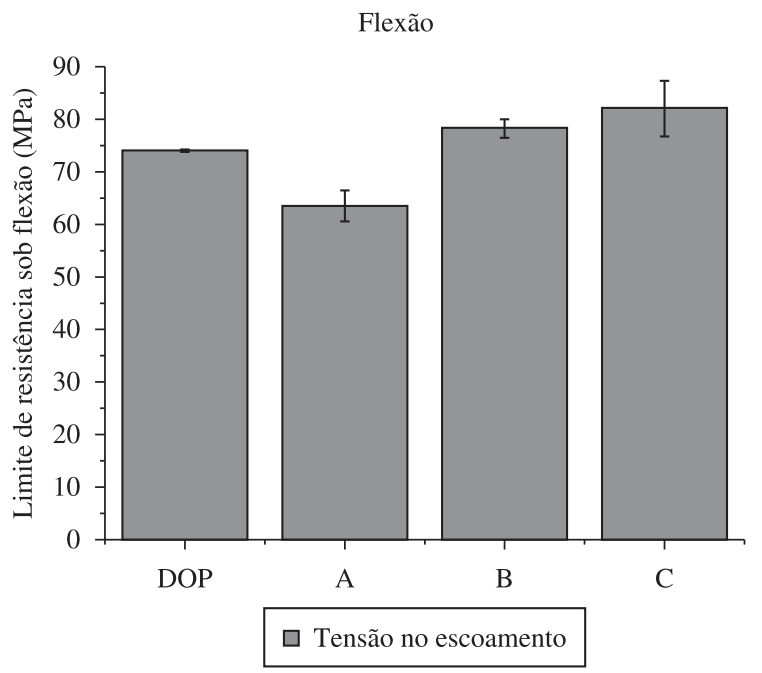

Figura 7. Limite de resistência sob flexão para as diversas amostras: DOP; A; B e C.

Flexão

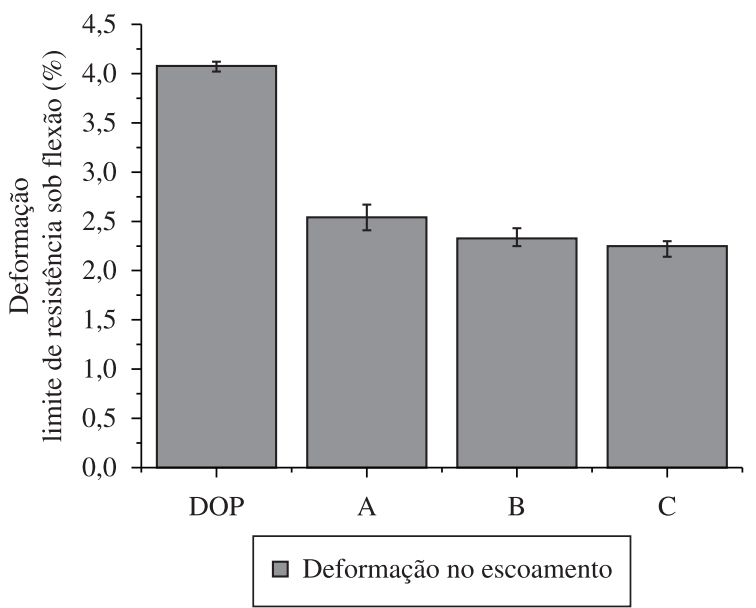

Figura 8. Deformação no limite de resistência a flexão para as diversas amostras: DOP; A; B e C.
A Figura 10 apresenta esta propriedade. Os compósitos deveriam apresentar resultados de HDT maiores do que a amostra DOP devido à presença das fibras de vidro nos compósitos. Entretanto os compósitos apresentavam em sua formulação óleo de soja epoxidado que pode ter reduzido a HDT. Em relação aos compósitos, a amostra $\mathrm{C}$ apresentou valores ligeiramente superiores as amostras A e B, por volta de $3,5 \%$, que corresponde $1,5^{\circ} \mathrm{C}$.

\section{Microscopia eletrônica de varredura (MEV) das superfícies criofaturadas de corpos de prova de tração (compósitos)}

De um modo geral todos os compósitos apresentaram excelente dispersão das fibras de vidro e boa adesão fibra-matriz conforme observado na Figura 11. Pode se notar que houve a formação de uma interface em todos os compósitos aliada a presença de matriz aderida à superfície das fibras. Nos compósitos $\mathrm{B}$ e $\mathrm{C}$ que apresentavam compatibilizantes em sua formulação houve a adesão de uma maior quantidade de matriz aderida à superfície das fibras

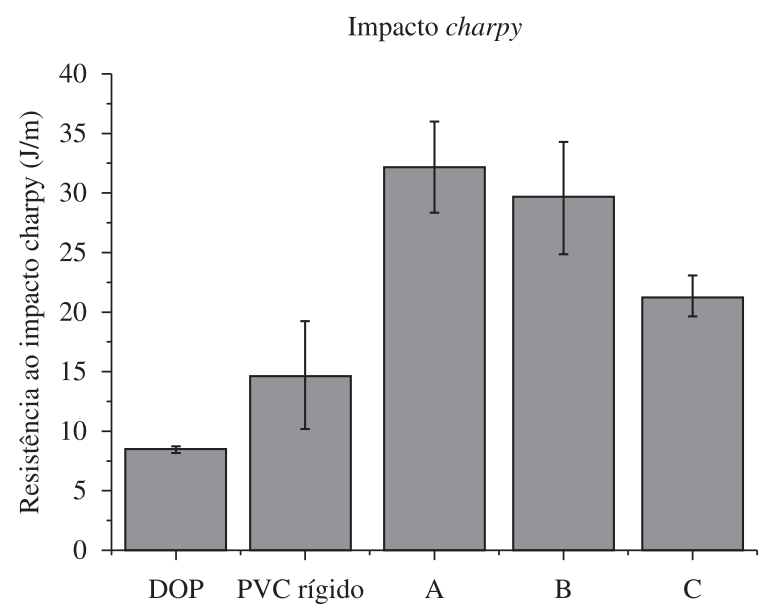

Figura 9. Resistência ao impacto charpy com entalhe $\left(\mathrm{J} \cdot \mathrm{m}^{-1}\right)$ para as diversas amostras: DOP; PVC Rígido; A; B e C.

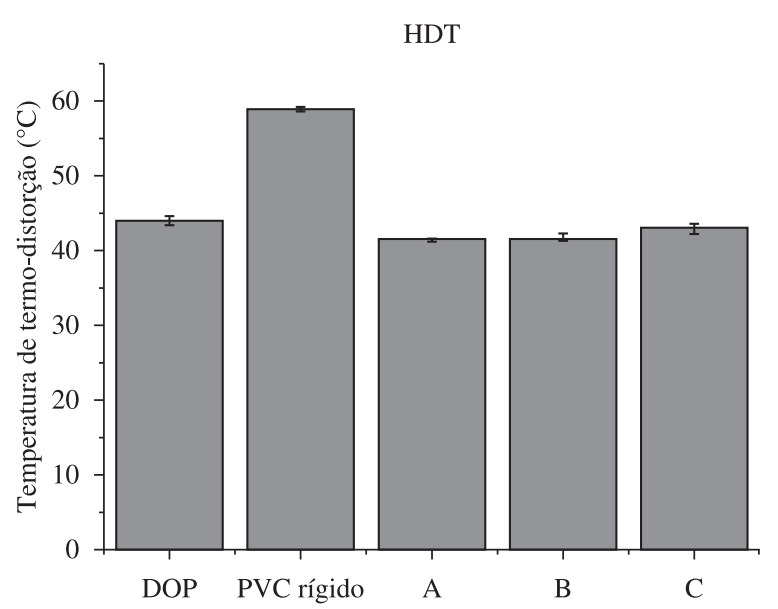

Figura 10. Temperatura de termo-distorção (HDT) para as diversas amostras: DOP; PVC Rígido; A; B e C. 


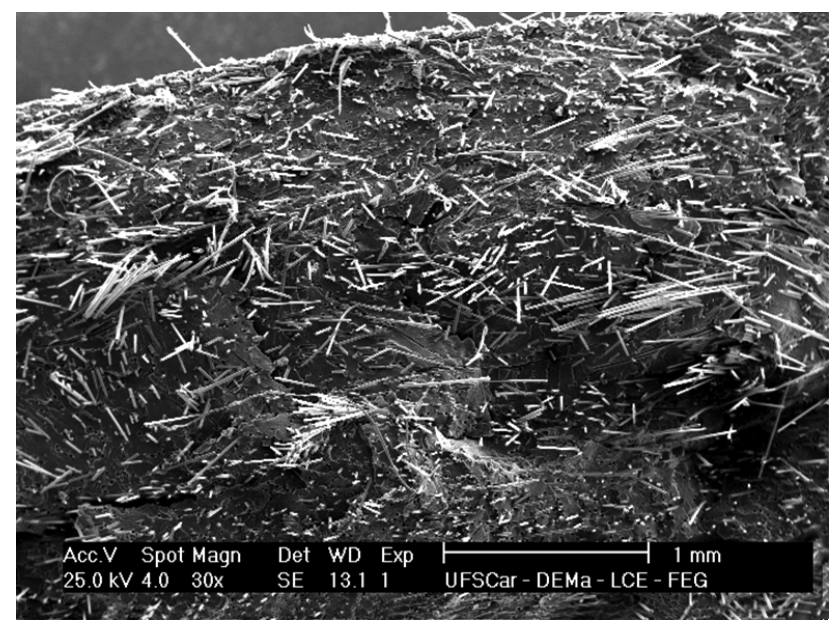

(a)

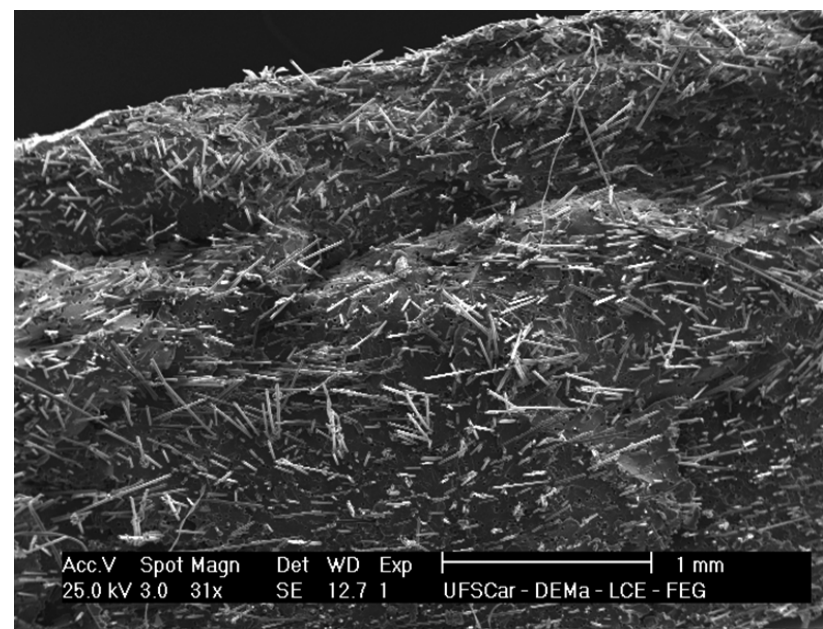

(c)

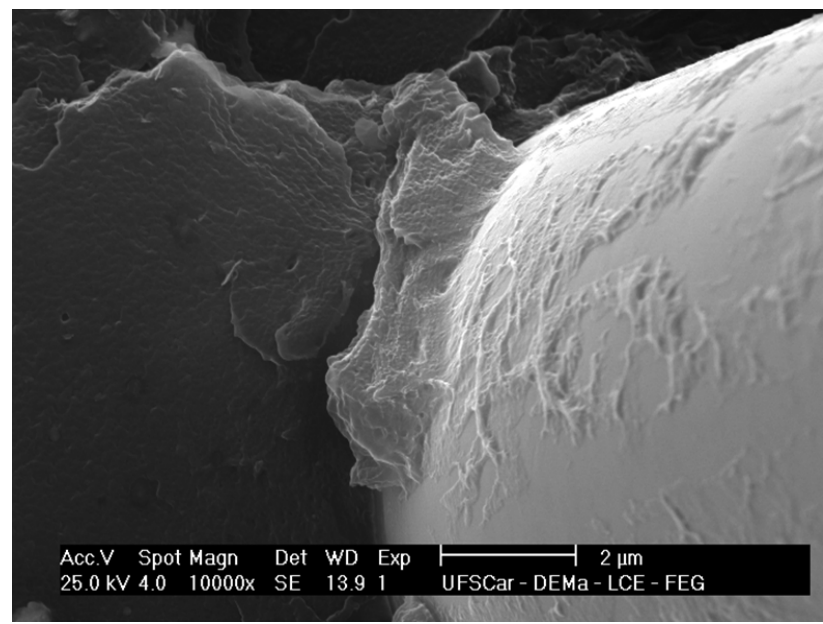

(e)

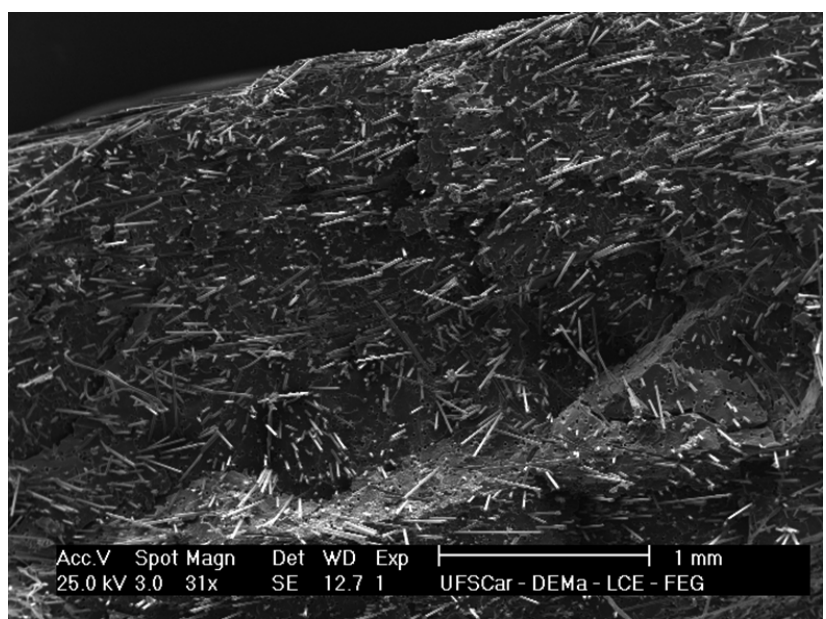

(b)

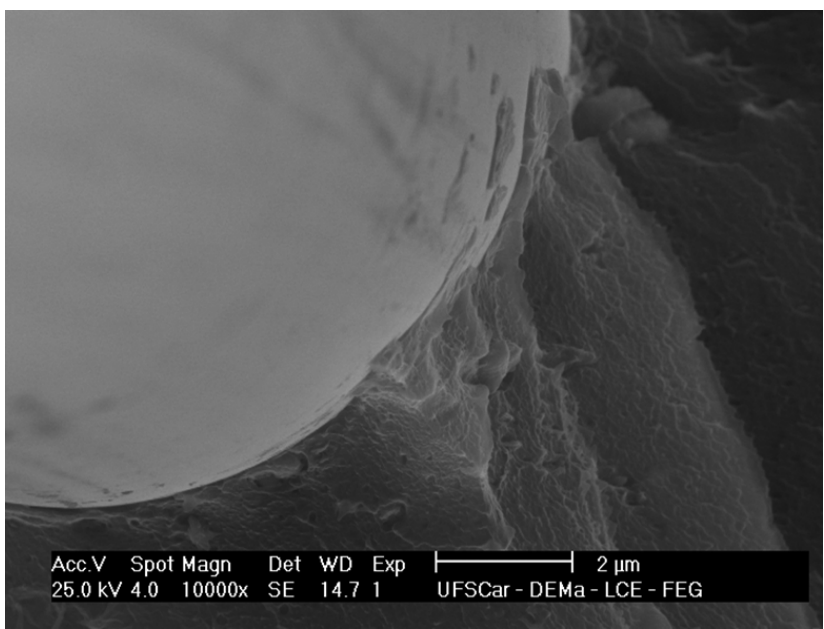

(d)

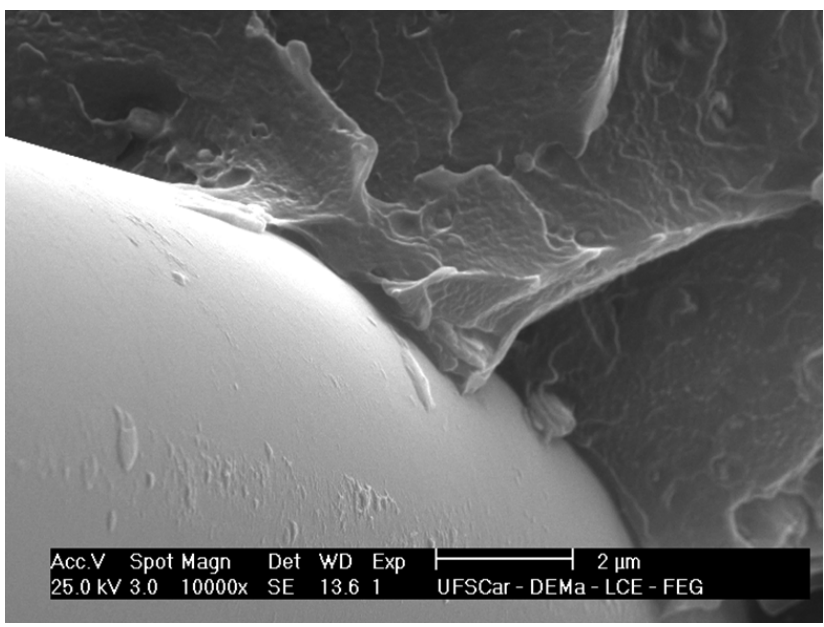

(f)

Figura 11. Micrografias das superfícies criofraturadas das amostras: a) A; b) B; e c) C (30-31×). d) A; e) B; e f) C (10.000-20.000×).

de vidro, porém no compósito B a adesão foi mais aleatória e no compósito $\mathrm{C}$ foi mais constante, ou seja, na maioria da superfície das fibras foi encontrada matriz aderida.

No balanço de propriedades todos os compósitos apresentaram desempenhos mecânicos superiores às amostras não reforçadas com fibras (DOP e PVC Rígido). Para as temperaturas de termo- distorção (HDT), todas as amostras que continham plastificantes (DOP, A, B , C), apresentaram resultados de HDT inferiores à amostra sem plastificante (PVC Rígido). A grande quantidade de plastificante $(11 \%$ em massa) possivelmente influenciou numa menor sensibilidade das propriedades mecânicas e da temperatura de termo-distorção (HDT) para com o uso de compatibilizantes. 
Após a avaliação por microscopia eletrônica de varredura, se pode notar que todos os compósitos apresentaram boa dispersão das fibras de vidro, baseado na boa distribuição das fibras na matriz; boa molhabilidade da matriz vinílica e boa adesão fibra-matriz com a formação de interface em todos os compósitos.

\section{Conclusões}

O reforçamento do PVC rígido com fibras de vidro longas foi alcançado com sucesso através da incorporação pelo processo (wire coating) de recobrimento da fibra de vidro contínua (rovings) por uma formulação de PVC plastificado, com posterior picotamento para a formação de grânulos de FV (com fibras de vidro já incorporadas ao PVC) para posterior alimentação direta nas máquinas de processamento. O processo de alimentação direta sem a necessidade de compostagem foi realizado também com sucesso na moldagem por injeção.

A presença dos compatibilizantes melhorou a adesão fibramatriz, porém, a grande quantidade de plastificante possivelmente pode ter influenciado na menor sensibilidade das propriedades para com o uso de compatibilizantes, o que mostra a tendência ao desenvolvimento de um composto com menor fração de plastificante para a melhoria das propriedades.

De um modo geral o trabalho desenvolveu um processo de incorporação inovador para área de vinílicos, utilizando fibras longas como reforços, que permitiu ao PVC poder ser utilizado em outras aplicações não antes possíveis, como para aplicações em peças técnicas de engenharia, em virtude das boas propriedades alcançadas.

\section{Agradecimentos}

Os autores agradecem as empresas Owens Corning; Karina Indústria e Comércio de Plásticos Ltda.; Lamine Tecnologia em Laminados Ltda.; Programa NEO PVC da Braskem e Agência CAPES pelo apoio recebido.

\section{Referências Bibliográficas}

1. Rodolfo, A. J.; Nunes, L. R. \& Ormanji, W. - "Tecnologia do PVC", Proeditores/Braskem, São Paulo (2006).

2. Titow, W. V. - "PVC Tecnology", Elsevier Applied Science Publishers, London (1984). http://dx.doi.org/10.1007/978-94-009-5614-8
3. Sousa, J. A. \& Hage Junior, E. - "Compósitos Termoplásticos. Tecnologia de Termoplásticos. Módulo 4", Universidade Federal de São Carlos, São Carlos (2005).

4. Lopes, P. E. - "Influência das Características do Compatibilizante de Polipropileno Maleificado nas Propriedades Mecânicas de Polipropileno Reforçado com Fibras de Vidro Curtas", Tese de Doutorado, Universidade Federal de São Carlos, Brasil (2003).

5. Chawla, K. K. - "Composite Materials: Science and Engineering", Springer-Verlag, New York (1998).

6. Murphy, J. - "Additives for Plastics Handbook", Elsevier Advanced Technology, Oxford (2001).

7. De, S. K. \& White, J. R. - "Short Fibre - Polymer Composites", Woodhead Publishing Limited, Cambridge (1996). http://dx.doi. org/10.1533/9781845698676

8. Souza Almeida, S. P. - “Avaliação das Propriedades Mecânicas de Compósitos Pultrudados de Matriz Polimérica com Reforço de Fibra de Vidro", Tese de Doutorado, Universidade Federal do Rio de Janeiro, Brasil (2004).

9. Thomason, J. L. - Compos. Part A, Appl. Sci. Manuf., 36, p. 477 (2005).

10. Thomason, J. L. \& Vlug, M. A. - Compos. Part A, Appl. Sci. Manuf., 27 (1996).

11. Thomason, J. L. \& Vlug, M. A. - Compos. Part A, Appl. Sci. Manuf., 28 (1996).

12. Thomason, J. L. - Compos. Sci. Technol., 61 (2001).

13. Feltran, M. B. \& Diaz, F. R. V. - Polímeros, 17 (2007).

14. Deanin, R. D. \& Michaels, G. C. - J. Vinyl Tech., 6 (1984).

15. Silverman, E. D. - Plastics Comp., 1, p.54 (1986).

16. Balow, M. J. \& Fuccella, D. C. - "Glass-Fiber-Reinforced Poly(Vinyl Chloride), a Valuable Engineering Thermoplastics", J. Vinyl Tech., 4, p. 73 (1982). http://dx.doi.org/10.1002/vnl.730040207

17. Summers, J. W.; Faber, E.; Kinson, P. L. \& Rabinovitch, E. B. - "Vinyl Composites - Fiberglass Reinforced PVC", J. Vinyl Tech., 12, p. 99 (1990). http://dx.doi.org/10.1002/vnl.730120211

18. Moriwaki, T. - Compos. Part A, Appl. Sci. Manuf., 27 (1996).

Enviado: 06/11/09

Reenviado: $11 / 01 / 10$

Aceito: 01/03/11

DOI: $10.1590 / S 0104-14282011005000065$ 